ISSN 1518-3483

Licenciado sob uma Licença Creative Commons

\title{
Educação escolar e currículo: uma abordagem cultural
}

School education and curriculum: a cultural approach

Educación escolar y currículo: un enfoque cultural

\section{Geyso Dongley Germinari, Daniela Pedroso*}

Universidade Federal do Paraná (UFPR)

\section{Resumo}

Este artigo é resultado de reflexões acerca da relação entre seleção de conteúdos de ensino e currículo compreendido como artefato social e cultural. Para o desenvolvimento de tal estudo, contou-se com um arcabouço teórico que introduz os três conceitos que fundamentam a presente análise: cultura, educação e currículo. Tais temas foram abordados à luz de autores selecionados no sentido de apontar diferentes maneiras de compreensão e apropriação dos mesmos no contexto escolar, além de subsidiar a discussão referente à tradição seletiva e à constituição dos saberes escolares. A pesquisa bibliográfica conduziu metodologicamente a análise. A contribuição deste trabalho pode ser apontada particularmente quanto à possibilidade que se concretizou de compreender teoricamente a

* GDG: Doutor em Educação, e-mail: geysog@gmail.com

DP: Doutoranda em Educação, e-mail: danielapedroso@hotmail.com 
especificidade dos conteúdos de ensino escolar selecionados pelos dispositivos curriculares e sua relação com a cultura, entidade na perspectiva social e histórica.

Palavras-chave: Educação Escolar. Currículo. Cultura.

\begin{abstract}
This paper is the result of reflections on the relationship between selection of teaching content and curriculum understood as social and cultural artifact. For the development of such a study, we used a theoretical framework that introduces the three concepts that underlie this analysis: culture, education and curriculum. These issues were addressed in the light of authors selected in order to point out different ways of understanding and ownership of them in schools, in addition to supporting the discussion relating to selective tradition and the establishment of school knowledge. The literature review conducted methodologically the analysis. The contribution of this work can be particularly pointed to the possibility that materialized theoretically understanding of the specificity of school education content selected by the curriculum devices and its relation to culture, social organization and historical perspective.
\end{abstract}

Keyword: Education School. Curriculum. Culture.

\title{
Resumen
}

Este artículo es el resultado de reflexiones sobre la relación entre la selección del contenido de la enseñanza y el currículo entendido como artefacto cultural y social. Para el desarrollo de un estudio de este tipo, hemos contado con un marco teórico que introduce los tres conceptos que subyacen en este análisis: la cultura, la educación y el currículo. Estas cuestiones fueron tratadas a la luz de los autores seleccionados con el fin de señalar las diferentes formas de entender y la propiedad de ellos en las escuelas, además de apoyar la discusión relativa a la tradición selectiva y el establecimiento del conocimiento escolar. La literatura llevó a cabo el análisis metodológicamente. La contribución de este trabajo puede ser particularmente indicadas a la posibilidad de que se materializó comprender teóricamente la 
especificidad del contenido de la enseñanza escolar seleccionados por los dispositivos del plan de estudios y su relación con la cultura, la organización social y perspectiva histórica.

Palabras clave: Educación escolar. Currículo. Cultura.

\section{Introdução}

O conceito de cultura expandiu nas últimas décadas com abordagens diversas que indicam diferentes maneiras de compreender o mundo contemporâneo, em seus diferentes âmbitos sociais e tem contribuído especialmente para desvelar as relações culturais presentes na educação escolar.

Por um lado, se tomar, como exemplo, o conceito de cultura defendido por Pinto (1979), como coetânea do processo de hominização, pelo qual o homem acumula experiências ao passo que vai se tornando capaz de realizar, possuidora de dois componentes, as ideias e a técnica, indissociável do processo de produção, percebe-se que a ideia de educação, inserida no processo de hominização, será defendida como processo de trabalho. Por outro lado, o proeminente teórico do currículo Michael Apple $(1982,1989)$ ressaltou o papel da cultura na escola e as relações com o desenvolvimento econômico que marcam os processos de seleção e distribuição do conhecimento escolar. Todavia, a abordagem cultural da escola defendida por Apple não significa desconsiderar a força do capitalismo, o caráter estrutural das relações de produção e poder da classe social.

Para Brandão (1995), embora não exista uma única forma ou modelo de educação é importante ressaltar que, em sentido amplo, a educação é oriunda da necessidade humana de transferência de saberes entre gerações. A educação como prática social, não se restringe ao domínio escolar, mas concretiza-se de acordo com as necessidades de cada cultura na manutenção de seu estilo de vida e na criação de "tipos de homens". 
Neste sentido, a necessidade de transmitir algo a alguém, seja no âmbito de participação no processo de produção de crenças e ideias, na qualificação e especificidades que envolvem as trocas de símbolos, na construção de tipos de sociedades e até mesmo na manutenção de ideias em prol da conservação de modelos e sociedades na perpetuação de hegemonias, envolve um conteúdo precedente. Segundo Forquin (1993, p. 10), "este conteúdo que se transmite na educação é sempre alguma coisa que nos precede, nos ultrapassa e nos institui enquanto sujeitos humanos, pode-se perfeitamente dar-lhe o nome de cultura".

Nessa direção, o capítulo pretende abordar o conceito de cultura para compreender a sua amplitude e possibilidades para pensar a educação escolar, uma vez que o conceito de cultura traz implicações sobre a relação escola e currículo. Percebe-se que o conceito de cultura, além de se transformar, ao longo do tempo, assim como as ideias circundantes e as concepções de homem e sociedade, possui tal amplitude que nos faz refletir juntamente com Forquin (1993, p. 15) no que se refere à educação escolar: "a escola não ensina senão uma parte extremamente restrita de tudo o que constitui a experiência coletiva, a cultura viva de uma comunidade humana". O conteúdo a ser ensinado é fruto da decantação, resultante da tradição seletiva, criando, assim, uma cultura geral correspondente aos interesses contemporâneos, conforme Williams (2003).

\section{O conceito de cultura na perspectiva de Raymond Williams}

Até o século XVIII, o termo cultura referia-se, principalmente, ao cultivo similar ao emprego agrícola, utilizado na lavoura e, portanto, material. Com o passar do tempo e com mudanças atribuídas às questões filosóficas, houve sua desconstrução e, no século XIX, a transformação em imaterial. Na contemporaneidade, a cultura pode ser reconhecida em suas duas configurações: material e imaterial ${ }^{1}$.

1 Segundo a UNESCO (Patrimônio cultural no Brasil, (C) UNESCO, URL), entende-se por patrimônio cultural imaterial as práticas, representações, expressões, conhecimentos e técnicas - junto com os 
Nessa transição, o cultivo deixa de ser relacionado a terra e passa a ter caráter de autocultivo. $\mathrm{O}$ homem complementa a natureza e suas limitações pelas transformações sociais. Mas, na transição do entendimento de cultivado pela ação do homem para a qualidade do ser culto, surge a preocupação de não se tornar reducionista e restrita a certa parcela da população.

Neste sentido, nasce o debate acerca de uma cultura comum, partindo da ideia que a mesma perdura quando originada de uma maioria popular e que se divide em consciente e inconsciente. A cultura comum não se concebe como cultura uniforme, uma vez que deve se levar em conta a desigualdade e a pluralidade oriundas de qualquer cultura real, já que é resultante do envolvimento de vários agentes. Esta visão é compartilhada por Eliot e Williams, embora suas concepções de cultura sejam divergentes em diversos pontos, como aponta Eagleton (2005, p. 168-169)

[...] essa é a diferença básica entre a idéia de uma cultura comum de Williams e a de Eliot. Para Williams, uma cultura é comum apenas quando feita coletivamente; para Eliot, uma cultura é comum mesmo quando sua elaboração é reservada aos privilegiados poucos. [...] A cultura comum de Williams é tanto mais quanto menos consciente do que a de Eliot: mais, porque envolve a participação ativa de todos os seus membros; menos, porque o que será produzido por essa colaboração não pode ser nem projetado de antemão, nem completamente conhecido durante o processo de construção.

Terry Eagleton (2005) constrói um arcabouço teórico complexo e fluente sobre a concepção de cultura, ao discorrer sobre o tema a partir de diferentes autores e acepções. Tendo como referência Raymond Williams, destaca seu pensamento de cultura como elemento constitutivo

instrumentos, objetos, artefatos e lugares culturais que lhes são associados - que as comunidades, os grupos e, em alguns casos, os indivíduos reconhecem como parte integrante de seu patrimônio cultural. O patrimônio cultural material é composto por objetos, monumentos, grupos de edifícios ou sítios que tenham um excepcional e universal valor histórico, estético, arqueológico, científico, etnológico ou antropológico. 
de outros processos sociais e não meramente de suas representações ou reflexões. As contribuições de Raymond Williams para os estudos culturais são inegáveis, dedicou sua vida aos estudos sobre questões práticoteóricas que envolvem o conceito de cultura, a partir da tradição do pensamento marxista.

A análise cultural marxista da sociedade baseou comumente sua interpretação na ideia da existência de infraestrutura econômica determinada e uma superestrutura determinada, nessa esfera localizam-se estruturas de pensamento, ideias, moral e consciência (WILLIAMS, 2011a; 2011b). Nessa perspectiva, a dimensão da cultura, entendida como significados e valores, portanto, localizada na superestrutura, torna-se uma instância determinada pela infraestrutura, ou seja, um mero reflexo da economia. A cultura como elemento secundário da sociedade não tem a capacidade de produção da realidade. Williams (2011a; 2011b), rompe com essa compreensão e defende a centralidade da cultura.

Assim, o autor supera as interpretações marxistas mecanicistas, as quais colocam a cultura como reflexo do sistema econômico dominante, e aproxima-se da compreensão da cultura ma relação com a totalidade social do modo de vida. Williams (2011a, p. 306), toma a literatura como exemplo: "[...] ainda que o elemento econômico seja determinante, ele determina todo um modo de vida, e é a esse modo vida, e não unicamente ao sistema econômico, que a literatura tem de ser relacionada".

A definição de cultura de Williams (2003) está relacionada a três categorias: a ideal, a documental e a social. Considera a primeira categoria como um estado, processo ou representação da perfeição humana expressa por meio da vida e das obras e por seus valores intrínsecos; a segunda, como o conjunto das obras intelectuais e imaginárias que registram de diversos modos o pensamento e a experiência humana, sendo assim uma atividade crítica; e a terceira, a cultura como descrição de determinado modo de vida que expressa certos significados e valores.

Para Williams (2003) as três definições são necessárias para que possamos compreender os processos culturais de forma ampla, de maneira que práticas sociais e produções culturais sejam entendidas como 
sistemas de significações. A cultura, neste sentido, deve produzir a realidade, em vez de meramente refleti-la ou representá-la, pois constitui o mundo real na medida em que a força produtiva interage com ele, por intermédio de "práticas significativas" como a linguagem, as artes, a moda e a publicidade, entre outras formas que integram esse campo complexo e extenso (WILLIAMS, 1992, p. 13).

Sendo assim, a cultura se estrutura como resposta ao modo de vida do qual seu autor emerge, uma vez que "as práticas sociais e os hábitos mentais se misturam às formas de produção e de organização sócio-econômicas a ponto de estruturarem, em termos de sentido, a vida e suas experiências", conforme aponta Araujo (2004, p. 5) em seu estudo sobre educação e cultura na perspectiva de Williams.

A cultura, na perspectiva de Williams (2011a; 2011b), faz parte do processo integral da vida, tem caráter social, caracterizada pela complexa interdependência de todos os aspectos da realidade social, inserese na dinâmica social, marcada pelas mudanças históricas da produção social da vida humana.

Ainda, na esteira de Williams (2011a; 2011b), é relevante destacar o conceito de cultura comum. Ele afirma que a cultura é comum quando construída pela prática social coletiva, como define como expõe Terry Eagleton (2005, p. 169): “[...] para Williams, uma cultura comum é aquela que é continuamente refeita e redefinida pela prática coletiva de seus membros, e não aquela nas quais valores criados pelos poucos são depois assumidos e vividos passivamente pelos muitos".

Segundo Williams (2011a; 2011b), a cultura de uma sociedade, no seu cotidiano mais trivial ou nos seus aspectos mais sofisticas, como artes e literatura, é uma edificação de toda a sociedade, independente da classe social. As práticas cotidianas e as criações artísticas, por exemplo, estão inseridas numa mesma base social comum. Cevasco destaca (2001, p. 48) 
Explicitando um pouco melhor: a definição mais prosaica, de cultura como modo de vida, e a mais elevada, de cultura como os produtos artísticos, não representam alternativas excludentes: o valor de uma obra de arte individual reside na integração particular da experiência que sua forma plasma. Essa integração é uma seleção e uma resposta ao modo de vida coletivo sem o qual a arte não pode ser compreendida e nem mesmo chegar a existir, uma vez que seu material e seu significa vêm deste coletivo.

Nessa direção, Jean-Claude Forquin (1993, p. 36), fundamentado em Williams, descreve que,

Cada geração, no interior de um mesmo país, recebe de herança uma certa tradição intelectual e artística que representa sempre muito mais do que o produto de uma única classe social [...] em cada época, quando uma classe social particular pode ser dita em posição 'dominante' ela está longe de ter, em matéria de cultura, um monopólio da criação e do controle: o estoque comum dos bens simbólicos é sempre alimentado pelos indivíduos de diversas proveniências sociais mesmo que a contribuição de cada grupo seja desigual.

A concepção de cultura comum rompe com a ideia de cultura elaborada unicamente pela classe dominante para a classe dominante, como a única capaz de produzir cultura autêntica; para Williams (2011a; 2011b) há um longo processo de seleção, interpretação e apropriação de determinados produtos culturais (bens comuns) pelas classes dominantes, essa apropriação serve como forma de distinção e perpetuação do poder sobre as classes sociais menos favorecidas economicamente que formam uma sociedade. Tal processo Williams (2011b, p. 54) chama de "Tradição Seletiva":

O que, nos termos de uma cultura dominante efetiva, e sempre assumida como 'a tradição', 'o passado significativo. Mas sempre o ponto-chave é a seleção - a forma pela qual, a partir de toda uma área do passado e do presente, certos significados e práticas são escolhidos 
e enfatizados, enquanto outros significados e práticas são negligenciados e excluídos. De modo ainda mais importante, alguns desses significados e práticas são reinterpretados, diluídos ou colocados em formas que dão suporte ou, ao menos, não contradizem os outros elementos dentro da cultura dominante eficaz.

O contínuo fazer e refazer da cultura dominante acontece nos processos de educação; na formação social mais ampla, como a família; na organização do trabalho; nas práticas cotidianas; na tradição seletiva em um plano intelectual e teórico. Essas forças colaboram para manutenção da cultura dominante, operando de modo específico no contínuo trabalho de conformação dessa cultura dominante.

A educação escolar, objeto do presente texto, insere-se em processos significativos de seleção, conservação e legitimação da cultura dominante.

A escola transmite em forma de conteúdos às novas gerações uma parcela restrita da cultura produzida pela experiência humana coletiva. Assim, os conteúdos de ensino, substância primordial do trabalho pedagógico, resultam de um processo de seleção no interior da cultura que se sedimenta ao longo do tempo, como tradição. Além da seleção cultural, a educação escolar realiza a reorganização didática dos elementos da cultura destinados ao ensino/aprendizagem das novas gerações. Como afirma Forquin (1993, p. 15):

Isto significa dizer que a educação não transmite jamais a cultura, considerada como um patrimônio simbólico unitário e imperiosamente coerente. Nem sequer diremos que ela transmite fielmente uma cultura ou culturas (no sentido dos etnólogos e dos sociólogos): ela transmite, no máximo, algo da cultura, elementos de cultura, entre os quais não há forçosamente homogeneidade, que podem provir de fontes diversas, ser épocas diferentes [...].

A seleção cultural empreendida pela escola - realizada por meio do currículo, programas de ensino, materiais didáticos, políticas públicas e práticas pedagógicas - conserva determinados elementos da 
cultura em detrimento de outros, é intrínseca a ideia de valor e hierarquia no processo de seleção e manutenção dos conteúdos a serem ensinados, desta forma, a educação escolar promove e excluí conteúdos, metodologias de ensino, princípios didáticos e valores, conforme as contingências históricas.

\section{Currículo como seleção cultural}

Antes de darmos início às reflexões referentes ao currículo, se faz necessário distinguirmos com maior clareza determinados termos empregados até o momento e que continuarão sendo utilizados no decorrer do texto. São eles: conhecimento, saberes e conteúdos. Para isso, recorremos a Gamboa (2009, p. 13)

[...] é necessário explicitar as diferenças entre conhecimento e saberes. Eles se colocam de forma oposta e contraditória, no mesmo processo. Enquanto o conhecimento se refere à parte dinâmica, ao processo de qualificar perguntas e produzir as respostas novas, os saberes se referem ao produto, à resposta elaborada, fechada, empacotada, sistematizada para ser distribuída, divulgada e consumida. Nesse sentido, conhecimento e saberes, embora contrários na funcionalidade, estão juntos na dinâmica dialética entre perguntas e respostas sobre um determinado fenômeno ou objeto. No contexto da organização escolar, os conhecimentos elaborados e acumulados pela humanidade são apropriados na forma de saberes e transformados em conteúdos didáticos e matérias curriculares.

O autor enfatiza que a denominação saberes escolares é a mais apropriada ao contexto da organização escolar. Com relação ao termo conteúdo, segundo Gimeno Sacristán (1998, p. 150),

[...] nos é apresentado carregado de uma significação antes intelectualista e culturalista, própria da tradição dominante das instituições escolares nas quais foi forjado e utilizado. [...] Por conteúdo se entenderam os resumos de cultura acadêmica que compunham os programas 
escolares em matérias e disciplinas diversas. É, por outro lado, um conceito que reflete a perspectiva dos que decidem o que ensinar e dos que ensinam, por isso, quando fizemos alusão aos conteúdos, costumamos nos referir ao que se pretende transmitir ou que outros assimilem, o que na realidade é muito diferente dos conteúdos reais implícitos nos resultados que o aluno/a obtém. [...] Os conteúdos compreendem todas as aprendizagens que os alunos/as devem alcançar para progredir nas direções que marcam os fins da educação numa etapa de escolarização, em qualquer área ou fora delas, e para tal é necessário estimular comportamentos, adquirir valores, atitudes e habilidades de pensamento, além de conhecimentos.

E ainda em relação ao conteúdo, o autor defende que se trata de "algo mais que uma seleção de conhecimentos pertencentes a diversos âmbitos do saber elaborado e formalizado" (GIMENO SACRISTÁN, 2000, p. 55). Com a ampliação dos conceitos apresentados, daremos continuidade às reflexões referentes ao currículo.

Podemos compreender melhor a noção de currículo quando nos remetemos ao pensamento de Williams (2003) de que os conteúdos do ensino são resultantes de uma seleção realizada no seio da cultura e, portanto, não se ensina a totalidade que compõe uma cultura, e sim uma combinação particular de ênfases e omissões, ou seja, um determinado repertório.

Mas, se levarmos em conta a ressalva de Gimeno Sacristán (1998, p. 126) de que o "conceito de currículo é bastante elástico; poderia ser qualificado de impreciso porque pode significar coisas distintas, segundo o enfoque que o desenvolva", faz-se necessário um aprofundamento.

Por currículo se entende, geralmente, tudo que é suposto de ser ensinado ou aprendido, segundo uma ordem determinada de programação e sob a responsabilidade de uma instituição de educação formal, nos limites de um ciclo de estudos. Por extensão, o termo me parece fazer referência ao conjunto dos conteúdos cognitivos e simbólicos (saberes, competências, representações, tendências, valores) transmitidos (de modo explícito ou implícito) nas práticas pedagógicas e nas situações de escolarização, isto 
é, tudo aquilo a que poderíamos chamar de dimensão cognitiva e cultural da educação escolar (FORQUIN, 2000, p. 48).

A definição de Forquin (2000) traz um sentido amplo de currículo e não meramente técnico, possibilitando vários tipos de enfoques. $\mathrm{O}$ que nos interessa discutir aqui é o currículo como artefato social e cultural. Ou seja, o currículo em suas determinações sociais e suas produções contextuais. Neste sentido, o currículo não pode ser considerado inocente ou neutro no que se refere à transmissão desinteressada de conhecimento, conforme Moreira e Silva (2001, p. 14), “o currículo está implicado em relações de poder, o currículo transmite visões sociais particulares e interessadas, o currículo produz identidades individuais e sociais particulares".

Se o currículo tem uma intencionalidade relacionada a determinado modelo social e, consequentemente, a um modelo de ser humano, privilegiará certos conhecimentos em detrimentos de outros. Sendo assim, múltiplos elementos estão em jogo, implicados em relações de poder, configurando um terreno privilegiado da política cultural. Em tal perspectiva, quem tem força nessa política impõe ao mundo suas representações, ou seja, o universo simbólico de sua cultura particular.

Então, podemos compreender o currículo conforme a acepção de Lawton²: "o modo pelo qual as prioridades são decididas e postas em prática" (1975, apud FORQUIN, 1993, p. 25). Mas como as prioridades são decididas ou o que pode ser considerado prioridade e, portanto, constituinte do currículo?

Se buscarmos a resposta em Forquin (2000, p. 47), perceberemos que o autor discute no que se refere à prioridade "aquilo que é suscetível de ser ensinado nas escolas", a controvérsia entre o relativismo e o universalismo, tendo como resultado princípios contraditórios de interpretação e de orientação. Para o mesmo, só é possível ensinar algo quando existe o reconhecimento de seu valor, ou seja, que haja uma legitimação por parte daqueles a quem o ensino se dirige, os estudantes. Mas deve ser primeiramente reconhecido por quem ensina, os professores. "Todo ensino se

2 LAWTON, D. Class, culture and the curriculum. Londres: Routledge and Kegan Paul, 1975. 
efetiva a partir da pressuposição de seu próprio valor" (FORQUIN, 2000, p. 50). O que nos conduz aos seguintes questionamentos: Se todo ensino inscreve-se necessariamente em um horizonte de valor e verdade, como o autor afirma que valores e verdades cabem à escola ensinar? Quais valores estéticos, atitudes morais e sociais devem ser ensinados? Serão os da cultura hegemônica ou os das minorias no âmbito das culturas locais?

Com isso, não se quer reduzir o universalismo programático da cultura escolar ao universalismo sem memória e descontextualizado do pensamento científico e tecnológico moderno, conforme ressalta Forquin (2000), mas apontar para uma seleção cultural que proporcione ao estudante a compreensão de um mundo sem fronteiras ou limites, que contribua para a construção de representações sobre si e sobre o mundo.

Educar, ensinar, é colocar alguém em presença de certos elementos da cultura a fim de que ele deles se nutra, que ele os incorpore à sua substância, que ele construa sua identidade intelectual e pessoal em função deles. Ora, um tal projeto repousa necessariamente, num momento ou noutro, sobre uma concepção seletiva e normativa da cultura (FORQUIN, 1993, p. 168).

Uma vez que já verificamos a impossibilidade de se ensinar tudo da cultura e, portanto, a necessidade de efetuar recortes a fim de torná-la assimilável, resta discutirmos como se realiza tal seleção. De acordo com Williams (2003), a cultura pode ser compreendida como objeto de e para a seleção. Neste sentido, ao mesmo tempo em que corresponde a escolhas culturais fundamentais, passa a ser o instrumento gerador dessas mesmas escolhas. Para o autor o conteúdo da educação, que se modifica ao longo do tempo, é fruto de escolhas sociais. Em tais escolhas, alguns aspectos da cultura do passado permanecem vivos e carregados de sentido no presente. Outros, no entanto, são descartados por motivo variados, como a crença em sua irrelevância, o silenciamento de determinado acontecimento, a substituição por acontecimentos recentes, entre outras possibilidades. O que corresponderia à tradição seletiva. Ou seja, a tradição seria o passado considerado relevante e por seletiva corresponderia "a 
forma em que, de todo um campo possível de passado e presente, escolhem-se como importantes determinados significados e práticas, ao passo que outros são negligenciados e excluídos" (WILLIAMS ${ }^{3}, 1973$ apud APPLE, 1982, p. 15).

Conforme o autor, é a partir do conceito de tradição seletiva que se interpreta a seleção cultural. De acordo com Lawton (apud FORQUIN, 1993), por seleção cultural podemos compreender os recortes efetuados no interior da cultura. Porém, é muito importante entendermos o funcionamento de uma tradição seletiva para que possamos compreender o ensino (WILLIAMS, 2003). Segundo o autor, a seleção inicia dentro de um mesmo período. De toda uma gama de atividades algumas são selecionadas por serem valorizadas e a ênfase do ensino é colocada sobre elas. Em geral, a seleção está relacionada a organização de todo um período, no entanto, tais valores e ênfases podem não ser confirmados, mais tarde. Também defende ser muito mais fácil valorar o passado do que o presente. O passado e a tradição são mais fáceis de serem defendidos, pois já aconteceram e, portanto, foram perpetuados de alguma forma e por alguém. Já o presente, por estar em construção, não tem o aval de outras gerações.

A tradição seletiva cria, em um nível, uma cultura humana geral, em outro, o registro histórico de uma determinada sociedade, e em um terceiro, o mais difícil de aceitar e avaliar, a rejeição de parte significativa do que foi outrora uma cultura viva. Dentro de uma dada sociedade, a seleção será regida por muitos Interesses especiais, inclusive os de classe (WILLIAMS, 2003, p. 60).

No trecho acima, podemos perceber que Williams, ao desenvolver seu pensamento sobre a tradição seletiva, volta a contemplar as três categorias de cultura (ideal, documental e social), apresentadas no início do capítulo, quando discutimos as definições de cultura. Se as três

3 WILLIAMS, R. Base and superstructure in Marxist cultural theory. Shooling and capitalism. London: Roger Dale et al., 1973. 
categorias são necessárias para que possamos compreender os processos culturais de forma ampla, o mesmo ocorre com relação à tradição seletiva.

Outra questão importante a ser considerada é que a tradição seletiva inevitavelmente seguirá os padrões de crescimento de uma sociedade e, para que esse crescimento seja contínuo, a relevância das obras passadas pode ser imprevisível. Portanto, essa tradição pode vir a sofrer modificações com o tempo. Sendo assim, "a tradição cultural não é só uma seleção, mas também uma interpretação” (WILLIAMS, 2003, p. 61). Uma interpretação leva a marca de autoria, ou seja, ela corresponde a uma visão realizada a partir do ângulo ou viés de quem a fez, seja este, temporal, político ou social.

Independente das características e das perspectivas que norteiam as diferentes instituições escolares, a conservação e a transmissão da herança cultural do passado constituem uma das funções essenciais da educação em todas as sociedades, conforme aponta Forquin (1992). No entanto, é necessário termos em mente que tal reprodução se realiza a partir de uma reinterpretação do que se acredita ser necessário conservar. O que vai ao encontro da reflexão de Williams sobre a tradição seletiva, apresentada anteriormente.

Se, por um lado, verificamos a necessidade de se perpetuar determinados acontecimentos, fatos ou conhecimentos; por outro lado, há necessidade de eliminar outros tantos no sentido de não serem considerados primordiais ou tão relevantes a ponto de continuarem a ser transmitidos.

Na tradição humanística clássica, conforme Forquin (1992), o processo de seleção ocorre na forma de decantação e de cristalização

O trivial e o medíocre caem no esquecimento, enquanto que perdura, vindo a enriquecer o tesouro comum dos homens, aquilo que as gerações produzem de mais forte, de mais original e de mais incontestável, que a escola e a universidade tem justamente por papel identificar, de consagrar e de transmitir (FORQUIN, 1992, p. 29). 
O que corresponde à universalidade, ou seja, ao conjunto de obras intelectuais e artísticas de valor permanente, considerado como o legado da humanidade. Para Williams ${ }^{4}$ (1961, apud FORQUIN, 1992) esse trabalho de decantação e de cristalização não obedeceria somente a motivações intrínsecas ou referentes à excelência universal, mas comportaria uma parte arbitrária e, portanto, uma reinvenção da memória cultural.

Outro aspecto presente na seleção cultural escolar abordado por Forquin (1992) é que a mesma não se limita ao passado, mas também ocorre sobre aquilo que constitui o presente. Determinados valores, tipos de conhecimentos, certas atitudes são considerados como importantes de serem transmitidas às gerações futuras em detrimento de outros. Como já discutimos anteriormente, somente parte de tudo aquilo que constitui a cultura é passível de ser transmitida em um tempo limitado, correspondente ao da educação escolar.

Diferentes escolas podem ter hierarquias de prioridades divergentes, mas todos os docentes e todas as escolas fazem seleções de um tipo ou de outro no interior da cultura. Proponho utilizar o termo currículo para designar essas seleções (LAWTON ${ }^{5}, 1975$ apud FORQUIN, 1992, p. 31).

O currículo a que se refere Lawton, conforme apresentado anteriormente, representa uma versão arbitrária de demarcação do que pode ou deve ser transmitido num determinado contexto institucionalizado, no caso, a escola. Mas existe uma diferença entre o que é pretendido ensinar e aquilo que é realmente ensinado, pois, embora a escola tenha a pretensão de transmitir o produto de uma determinada seleção, o que será realmente compreendido e apreendido pelos estudantes dependerá das condições de recepção dos mesmos, assim como do contexto social e cultural.

4 WILLIAMS, R. The long revolution. Londres: Chato and Windus, 1961.

5 LAWTON, D. Class, culture and the curriculum. Londres: Routledge and Kegan, 1975. 
Nesse sentido, lembramos que não basta efetuar uma seleção entre os saberes e os materiais culturais disponíveis em determinado momento de uma sociedade, como adverte Forquin (1992), para que se torne efetivamente transmissível e assimilável pelos estudantes, é necessário que se efetue um trabalho de reorganização, de reestruturação e de transposição didática.

Vejamos o conceito de transposição didática apresentado por Chevallard (2000, p. 16)

O conceito de transposição didática remete ao caminho do saber sábio ao saber ensinado e, portanto, a distância obrigatória que os separa [...]. Para o ensino, é uma ferramenta que permite refletir, se distanciar, analisar as evidências, questionar as idéias simples, rejeitar a familiaridade enganosa de seu objeto de estudo. [...] É um dos instrumentos de ruptura que o ensino deve exercer para tornar seu próprio domínio, é aquele pelo qual o saber, na problemática do ensino, passa da potência ao ato.

Para Chevallard (2000) a transposição didática permite a distinção de três patamares do saber: o saber sábio constituído pelo produto da atividade científica; o saber a ensinar correspondente ao presente nos livros didáticos, definidos nas propostas curriculares, a cargo dos professores; e o saber ensinado, aquele que foi absorvido pelos estudantes.

Para o autor, a transposição didática operacionaliza o ensino dos saberes sábios, tornando-os acessíveis aos estudantes. Não no sentido de uma simplificação de saberes complexos, e sim no resultado de uma construção qualitativa diferente. Para que tal seja possível, é necessário que o saber em questão sofra certas transformações e, assim, possa satisfazer determinados requisitos específicos do ensino. Estas transformações podem ser determinadas por diversas esferas, constituídas por grupos que exercem pressão e que passam a moldar os saberes escolares. Pesquisadores, cientistas, autores de livros didáticos, especialistas, o poder político, os currículos e os professores compõem esses grupos. Para Chevallard (2000), tais grupos constituem a noosfera. 
Segundo o mesmo, a noosfera pode ser considerada como o centro operacional do processo de transposição didática. Nela é produzido todo tipo de conflito entre o sistema e o entorno, além de ser um lugar privilegiado de expressão. Se houver necessidade de modificação de determinado ensino, será por meio da noosfera que ocorrerá a mediação.

Com relação específica aos saberes escolares, é importante termos em mente que os mesmos são marcados pelo modo propriamente escolar, ou seja, a organização dos estudos em função do tempo, a divisão das atividades neste tempo, a duração dada a cada uma delas, a categorização hierárquica de tais atividades, sua classificação em notas, entre outras formas próprias do contexto escolar.

A cultura escolar apresenta-se assim como uma "cultura segunda" com relação à cultura de criação ou de invenção, uma cultura derivada e transposta, subordinada inteiramente a uma função de mediação didática e determinada pelos imperativos que decorrem desta função, como se vê através destes produtos e destes instrumentos característicos constituídos pelos programas e instruções oficiais, manual e materiais didáticos, temas de deveres e de exercícios, controles, notas, classificações e outras formas propriamente escolares de recompensas e de sanções (FORQUIN, 1992, p. 33-4).

Segundo Forquin (1993), a transposição didática impõe uma configuração cognitiva específica, saberes e modos de pensamento tipicamente escolares, constituindo uma cultura escolar que repousa sobre hábitos, critérios de excelência, sistemas de valores típicos, entre outros.

Os saberes escolares são organizados sob a forma de matérias ou disciplinas e, em determinadas instituições de ensino, ensinadas por docentes distintos, especialistas em suas áreas de atuação. Sendo assim, os saberes se destacam entre si na composição de diferentes disciplinas e estas na organização do currículo. Tais saberes, que são produtos de um processo contínuo de seleção cultural e de elaboração didática, são subordinados a uma hieraquização. Pois, conforme Forquin (1992), em um mesmo currículo, determinadas disciplinas são mais valorizadas do que 
outras, o que pode ser evidenciado pela carga horária ou na ponderação das avaliações.

O autor se opoia em Bernstei ${ }^{6}$ (1975, apud FORQUIN, 1992, p. 39) quando relaciona a maneira pela qual "uma sociedade seleciona, classifica, distribui, transmite e avalia os saberes destinados ao ensino" com a distribuição do poder em seu interior e, em consequência, no controle social dos comportamentos individuais. Pois, para o autor em questão, o discurso pedagógico se apropria de outros discursos para transmitir uma aquisição seletiva, corroborando com os princípios de controle e de distribuição de poder. Mas, se a escola modificasse sua organização e a compartimentação entre as matérias, que denomina por código serial, passando para o código integrado, favoreceria uma relação mais aberta, menos autoritária e menos hierárquica no interior da sala de aula e dos estabelecimentos de ensino em geral.

Isso nos faz retornar à discussão sobre currículo, mas agora com um enfoque específico dos modos de seleção, legitimação, organização e distribuição dos saberes escolares. Para isso, retomaremos Forquin (1993), em seus estudos sobre a sociologia do currículo, vertente de pesquisa e de reflexão sociológica, originária da Grã-Bretanha, no final dos anos 60 do século passado, que podem servir de base nesta análise curricular. Vinte anos depois, estes estudos resultaram no desdobramento da noção de currículo em três segmentos: currículo real, currículo formal ou oficial e currículo oculto. Em consequência, abriram-se novas frentes de pesquisas contextualizadas.

Por currículo real compreende-se aquilo que é efetivamente ensinado. O currículo formal ou oficial refere-se ao que consta nos programas oficiais, mas nem sempre contemplado no currículo real. Já o currículo oculto corresponde aos saberes, competências, representações, valores, que são adquiridos na escola, mas sem que estejam explicitados

6 BERNSTEIN, B. On the classification and framing of educational knowledge. In: YOUNG, M.F.D. (Org.). Knowledge and control: New directions for the sociology of education. Londres: CollierMacmillan, 1975. 
nos programas oficiais. Segundo Apple (1982), o termo "currículo oculto" foi empregado por Philip Jackson, entre outros teóricos, para designar o conjunto de valores morais, normativos e tendências, a serem padronizados pelas instituições educacionais. $\mathrm{O}$ autor ressalta, que "o currículo oculto nas escolas serve para reforçar as regras que cercam a natureza e os usos do conflito. Estabelece uma rede de suposições que, quando interiorizadas pelos estudantes, determinam os limites de legitimidade" (APPLE, 1982, p. 132).

Independentemente da especificidade do currículo, é importante que não nos esqueçamos de que o mesmo se constitui por um conjunto de conhecimentos selecionados a partir de inúmeras combinações possíveis. Porém, relembrando Lawton ${ }^{7}$ (1975 apud FORQUIN, 1992), que define o currículo escolar como o produto de uma seleção no interior da cultura de uma sociedade, toda seleção traz uma versão do que se pretende perpetuar.

Os conhecimentos que pelo currículo são selecionados, sistematizados, distribuídos e avaliados derivam de uma cultura concreta e ultrapassam os denominados "conhecimentos científicos" que, por definição, encontram-se expressos nos conteúdos próprios de diversas disciplinas. Trazem, por isso - por serem culturais - representações do que pode ser considerado conhecimento válido e não-conhecimento. Transmitem, assim, para além do "conhecimento científico", um modo de ver e classificar o mundo - vivido (PEDRA, 1993, p. 32).

É importante levarmos em conta que tal seleção ocorre em múltiplas esferas, ou níveis de mediação, conforme aponta Pedra (1993, p. 32). "[...] níveis não hierárquicos [...] e tampouco etapas de um processo de decantação pelo qual a seleção iria assumindo forma mais pura. São [...] níveis de resistências e reconstruções" (PEDRA, 1993, p. 33). Dois deles são apresentados pelo autor: o nível jurídico e o nível institucional.

7 LAWTON, D. Class, culture and the curriculum. Londres: Routledge and Kegan, 1975 
O primeiro define o que pode e ou deve ser ensinado e apresenta-se sob forma legal, como a Lei de Diretrizes e Bases da Educação Nacional, por exemplo. Mas é claro que a seleção de conteúdos não se esgota na ordenação jurídica, pois se faz necessária a implementação por meio de práticas efetivas, o que fica a cargo do segundo nível. De acordo com Pedra (1993), frequentemente encontram-se escolas totalmente inadequadas para o desenvolvimento correspondente às leis de ensino. Tal inadequação pode advir da precariedade das instalações ou da desqualificação do corpo docente. Sendo assim, a seleção inicial sofrerá, inevitavelmente, uma nova seleção para que possa se adequar à realidade da instituição. O autor conclui "se por um lado as estruturas jurídicas dimensionam e demarcam as amplitudes dos conhecimentos escolares, por outro lado, serão objeto de interpretação e reconstrução por aqueles que devem fazê-las funcionar" (PEDRA, 1993, p. 36).

Podemos estabelecer uma aproximação entre estas noções curriculares e os patamares do saber de Chevallard, apresentados anteriormente, no sentido de que se assemelham teoricamente, uma vez que fazem distinções entre as configurações de currículo correspondentes as distinções do saber. Com isso não queremos dizer que são a mesma coisa, apenas que compreendem os processos de aprendizagem de forma similar, do potencial ao real. Ou seja, do que se pretende ensinar ao que é apreendido pelos estudantes.

\section{Referências}

APPLE, M. W. Ideologia e currículo. São Paulo: Brasiliense, 1982.

APPLE, M. W. Educação e poder. Porto Alegre: Artes Médicas, 1989.

BRANDÃO, C. R. O que é educação. 33. ed. São Paulo: Brasiliense, 1995.

CEVASCO, M. E. E. Para ler Raymond Williams. São Paulo: Paz e Terra, 2001.

CHEVALLARD, Y. La transposición didáctica: del saber sábio al saber enseñado. Buenos Aires: Aique, 2000. 
EAGLETON, T. A idéia de cultura. São Paulo: Ed. UNESP, 2005.

FORQUIN, J.-C. Saberes escolares, imperativos didáticos e dinâmicas sociais. Teoria \& Educação, n. 5, p. 28-49, 1992.

FORQUIN, J. -C. Escola e cultura: as bases sociais e epistemológicas do conhecimento escolar. Porto Alegre: Artes Médicas, 1993.

FORQUIN, J.-C. O currículo entre o relativismo e o universalismo. Educação \& Sociedade, ano XXI, n. 73, p. 47-70, dez. 2000. Disponível em: <http://www.scielo.br/pdf/es/v21n73/4205.pdf>. Acesso em: 20 set. 2010.

GAMBOA, S. S. Saberes, conhecimentos e as pedagogias das perguntas e das respostas: atualidade de antigos conflitos. Práxis Educativa, Ponta Grossa, v. 4, n. 1, p. 9-19, jan./jun. 2009. Disponível em: 〈http//www.periodicos.uepg.br〉. Acesso em 12 ago. 2011.

GIMENO SACRISTÁN, J. O currículo: os conteúdos do ensino ou uma prática? In: GIMENO SACRISTÁN, J.; GÓMEZ, A. I. Pérez. Compreender e transformar o ensino. Porto Alegre: ArtMed, 1998. p. 119-148.

GIMENO SACRISTÁN, J. O que são os conteúdos do ensino? In: GIMENO SACRISTÁN, J.; GÓMEZ, A. I. Pérez. Compreender e transformar o ensino. Porto Alegre: ArtMed, 1998. p. 149-196.

GIMENO SACRISTÁN, J. O currículo: uma reflexão sobre a prática. Porto Alegre: ArtMed, 2000.

LAWTON, D. Class, culture and the curriculum. Londres: Routledge and Kegan, 1975.

MOREIRA, A. F. B.; SILVA, T. T. Sociologia e teoria crítica do currículo: uma introdução. In: MOREIRA, A. F. B.; SILVA, T. T. da (Orgs.). Currículo, cultura e sociedade. 12 ed. São Paulo: Cortez, 2001. p. 13-48.

PEDRA, J. A. Currículo e conhecimento: níveis de seleção do conteúdo. Em Aberto, ano 12, n. 58, p. 30 - 37, abr./jun. 1993. Disponível em: <http://www.dominiopublico.gov.br/download/texto/me000631.pdf> Acesso em: 22 jul. 2011. 
PINTO, Á. V. Ciência e existência. Rio de Janeiro: Paz e Terra, 1979.

WILLIAMS, R. Cultura. Rio de Janeiro: Paz e Terra, 1992.

WILLIAMS, R. La larga revolucíon. Buenos Aires: Nueva Visíon, 2003.

WILLIAMS, R. Cultura e sociedade: de coleridge a orwell. Petropólis: Vozes, 2011a.

WILLIAMS, R. Cultura e materialismo. São Paulo: Editora Unesp, 2011b.

WILLIAMS, R. Base and superstructure in Marxist cultural theory. Shooling and capitalism. London: Roger Dale et al., 1973.

WILLIAMS, R. The long revolution. Londres: Chato and Windus, 1961.

Recebido: 05/08/2016

Received: 08/05/2016

Aprovado: 30/08/2016

Approved: 08/30/2016 
